\title{
Smoking initiation is followed by the early acquisition of epigenetic change in cervical epithelium: a longitudinal study
}

\author{
YT Ma', SI Collins², LS Young', PG Murray' and CBJ Woodman*,I \\ 'Cancer Research UK Institute for Cancer Studies, School of Cancer Sciences, University of Birmingham, Birmingham, Edgbaston, B I 5 2TT, UK; \\ ${ }^{2}$ Cancer Research UK Clinical Trials Unit, School of Cancer Sciences, University of Birmingham, Birmingham, Edgbaston, BI5 2TT, UK
}

\begin{abstract}
BACKGROUND: To prove a causal link between an epigenetic change and an environmental or behavioural risk factor for a given disease, it is first necessary to show that the onset of exposure precedes the first detection of that epigenetic change in subjects who are still free of disease.

METHODS: Towards this end, a cohort of women aged 15-19 years, recruited soon after they first had sexual intercourse, were used to provide sequential observations on the relationship between cigarette smoking and the detection in cervical cytological samples of methylated forms of CDKN2A ( $p / 6)$ using nested methylation-specific polymerase chain reaction.

RESULTS: Among women who remained cytologically normal and who tested negative for human papillomavirus DNA in cervical smears during follow-up, those who first started to smoke during follow-up had an increased risk of acquiring CDKN2A methylation compared with never-smokers (odds ratio $=3.67 ; 95 \%$ confidence interval 1.09-12.33; $P=0.04$ ).

CONCLUSION: Smoking initiation is associated with the appearance of methylated forms of CDKN2A.

British Journal of Cancer (201 I) 1 04, I500-1504. doi: I0.1038/bjc.20 I I.I I3 www.bjcancer.com

Published online 12 April 201 I

(C) 201। Cancer Research UK
\end{abstract}

Keywords: smoking; epigenetic; methylation; cohort study; cervix

Exposure to certain behavioural and environmental factors during critical periods of development may result in persistent epigenetic changes, which have phenotypic consequences. For example, in humans, cross-sectional studies suggest that prenatal exposure to famine, in utero exposure to airborne polycyclic aromatic hydrocarbons, and childhood abuse are associated with aberrant methylation of the insulin-like growth factor IGF2, the long-chain acetyl-CoA synthetase ACSL3, and the hippocampal glucocorticoid receptor NR3C1, respectively (Heijmans et al, 2008; McGowan et al, 2009; Perera et al, 2009). Aberrant methylation of ACSL3 and $N R 3 C 1$ have in turn been associated with an increased risk of childhood asthma and suicide, respectively (McGowan et al, 2009; Perera et al, 2009).

Early age at smoking initiation is reported to increase the risk of both lung and cervical cancer, independent of smoking duration or intensity (Wiencke et al, 1990; Appleby et al, 2006). Such an association is biologically plausible because lung tissues continue to grow and develop into early adulthood, whereas the onset of sexual activity in young women is followed by the extensive remodelling of cervical epithelium, a process, which is accelerated by tobacco smoking (Wiencke and Kelsey, 2002; Hwang et al, 2009). However, evidence directly linking early age of smoking initiation to specific genetic, or epigenetic, changes is difficult to adduce. Although cross-sectional surveys, restricted to patients with cancer, have shown that the aberrant methylation of tumour suppressor genes (TSG) is associated with various aspects

*Correspondence: Dr CBJ Woodman; E-mail: c.b.woodman@bham.ac.uk Received 25 October 2010 ; revised 26 January 201 I; accepted II March 20I I; published online 12 April 2011 of smoking exposure, such surveys cannot distinguish those epigenetic changes that are a consequence of the disease process from those that are directly attributable to smoking (Kim et al, 2003; Marsit et al, 2005). More compelling evidence of smokinginduced epigenetic changes is dependent upon demonstrating, in disease-free individuals, that the onset of smoking precedes the detection of such changes. Such evidence requires a longitudinal study design. The accessibility of the cervix uteri, and the acceptability of the sampling process, presents the opportunity for making repeated observations, thus providing an ideal model for the exploration of the determinants of epigenetic changes. We have investigated the relationship between smoking initiation and the first appearance of methylated forms of the TSG CDKN2A ( $p 16)$, in cervical cytological samples taken from a cohort of young women who were recruited soon after they first had sexual intercourse.

\section{MATERIALS AND METHODS}

The study design and characteristics of the study population have been described elsewhere (Woodman et al, 2001). In brief, 2011 women aged 15-19 years were recruited from a single Brook Advisory Centre (a family planning clinic) in Birmingham, UK, between 1988 and 1992, and asked to re-attend at intervals of 6 months; follow-up ended on 31 August 1997. At recruitment, a standardised interview questionnaire was used to construct a detailed social, sexual, and behavioural risk-factor profile, including smoking. Sexual and smoking histories were updated at each follow-up visit. In addition, at each visit, two cervical cytological samples were taken using the same Ayres spatula; the 
first was used to prepare a smear for immediate cytological evaluation; and the second was placed into $10 \mathrm{ml}$ of phosphatebuffered saline and stored at $-80^{\circ} \mathrm{C}$ for subsequent virological examination. All women in whom a cervical cytological abnormality was identified were immediately referred to a dedicated research clinic for histological examination, irrespective of the severity of that abnormality. Colposcopic and cytological surveillance were maintained in these women, and treatment was postponed, until there was histological evidence of high-grade cervical intraepithelial neoplasia (CIN2 or CIN3), at which point women left the study. The study was approved by the appropriate Research Ethics Committee, and informed oral consent was obtained from all women.

\section{Study population}

The study population for this analysis was drawn from the 1075 women who were cytologically normal and who tested negative for human papillomavirus (HPV) DNA of any type in cervical samples taken at study entry, and who had further follow-up (Figure 1). From this cohort, we identified 97 women who first began to smoke during follow-up. Of these, 60 women had one or more consecutive samples immediately following smoking initiation when they also tested negative for HPV DNA and were cytologically normal. Excluded from further analyses were: 10 women in whom the last sample taken before smoking initiation was unavailable, or not evaluable; three women in whom this sample tested positive for methylated forms of CDKN2A; and nine women in whom the sample taken while they were smoking was unavailable, or not evaluable. The remaining 38 women entered the analysis comparing the risk of $C D K N 2 A$ methylation in incident smokers with that in never-smokers, but only follow-up time before the first detection of HPV DNA of any type, or of cytological abnormality, in cervical samples, was included.

\section{Assessment of smoking exposure and HPV status}

Assessment of smoking exposure. Smoking histories were updated at each follow-up visit. Smoking quantity was recorded as a categorical variable, with categories; 0 cigarettes smoked per day, $1-9,10-19,20-29,30-39$, and 40 or more. Cumulative smoking exposure was measured using pack-years, estimated as the midpoint of each smoking-quantity category (with the final category arbitrarily set to 45), multiplied by the length of the interval during which this quantity applied, and accumulated over the lifetime of the woman.

Assessment of HPV status. Cervical samples were tested for the presence of HPV DNA using a general primer $(\mathrm{GP} 5+/ \mathrm{GP} 6+)$ mediated polymerase chain reaction (PCR) and further PCR tests were performed with type-specific primers on samples, which were HPV-positive, using methods previously described (Woodman et al, 2001).

\section{Assessment of outcome status (DNA methylation of CDKN2A)}

DNA extraction. For the present study, the remainder of the stored sample was pelleted, and DNA isolated by digestion with proteinase $\mathrm{K}$, followed by standard phenol-chloroform extraction and ethanol precipitation. The NanoDrop ND-100 Spectrophotometer (Thermo Scientific, Wilmington, DE, USA) was used to measure DNA concentration, according to the manufacturer's instructions.

Bisulphite modification. DNA (200 ng) were isolated from each cervical cytological sample, and bisulphite modified using the EZ DNA Methylation-Gold Kit (Zymo Research, Irvine, CA, USA)

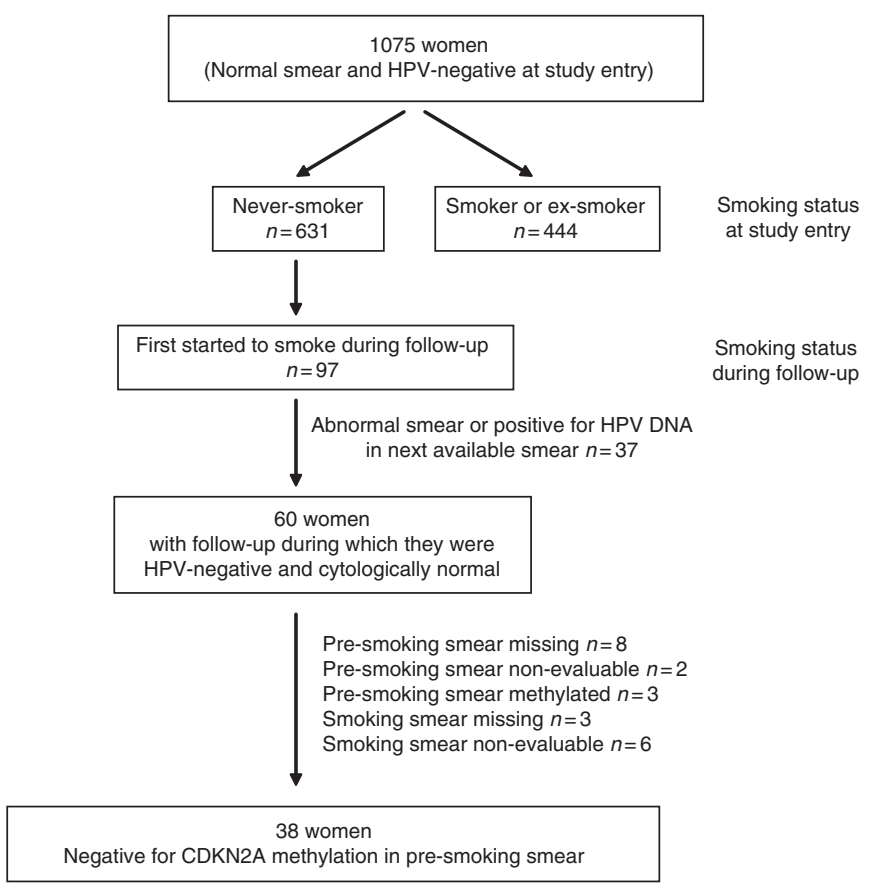

Figure I Flow diagram to show the selection of women for CDKN2A methylation analysis.

according to the manufacturer's instructions. The converted DNA was eluted in a final volume of $50 \mu \mathrm{l}$.

Methylation-specific PCR. As the samples were taken from young women with short smoking histories and were therefore likely to contain only a small number of cells with methylated forms, we elected to test for methylated forms of the CDKN2A gene using a nested two-stage methylation-specific PCR method (Palmisano et al, 2000). For the stage 1 PCR, $5 \mu \mathrm{l}$ of bisulphite-modified DNA were amplified in a $25 \mu \mathrm{l}$ volume using $12.5 \mu \mathrm{l}$ of GoTaq Green Mastermix (Promega UK Ltd, Southampton, UK), and $0.4 \mu \mathrm{moll}^{-1}$ of primer mix. The stage 1 primers recognise the bisulphitemodified template but do not discriminate between methylated and unmethylated alleles. Primer sequences used in this stage were: forward $5^{\prime}$-GAAGAAAGAGGAGGGGTTGG-3', and reverse $5^{\prime}$-CTACAAACCCTCTACCCACC-3'. Amplification was performed using a $\mathrm{P} \times 2$ Thermal Cycler (Thermo Scientific) with the following cycle conditions: $95^{\circ} \mathrm{C}$ for $10 \mathrm{~min}$, followed by 40 cycles of $95^{\circ} \mathrm{C}$ for $30 \mathrm{~s}, 56^{\circ} \mathrm{C}$ for $30 \mathrm{~s}, 72^{\circ} \mathrm{C}$ for $30 \mathrm{~s}$, and a final extension of $72^{\circ} \mathrm{C}$ for $10 \mathrm{~min}$. The stage 2 PCR was performed on $5 \mu \mathrm{l}$ of diluted stage 1 PCR product, using primers specific for methylated and unmethylated template. Amplification was performed in a $25 \mu \mathrm{l}$ volume, using $12.5 \mu \mathrm{l}$ of GoTaq Green Mastermix (Promega UK Ltd) and $0.4 \mu \mathrm{moll}^{-1}$ of primer mix. Primer sequences used in this stage were: forward unmethylated $5^{\prime}$-TTATTAGAGGGTGGGGTG GATTGT- $3^{\prime}$, reverse unmethylated $5^{\prime}$-CAACCCCAAACCACAACC ATAA- $3^{\prime}$, forward methylated $5^{\prime}$-TTATTAGAGGGTGGGGCGGAT CGC- $3^{\prime}$, and reverse methylated $5^{\prime}$-GACCCCGAACCGCGACCGT AA- $3^{\prime}$. For the stage 2 PCR, the annealing temperatures were increased to $65^{\circ} \mathrm{C}$ (unmethylated) and $70^{\circ} \mathrm{C}$ (methylated), and all cycling times were reduced to $15 \mathrm{~s}$. All stage 2 amplifications were performed in duplicate. Stage 2 PCR products were analysed using $2 \%$ agarose gel electrophoresis and ethidium bromide staining (Figure 2). Controls included CpGenome Universal methylated and unmethylated (vial B) DNA (Millipore (UK) Ltd, Watford, UK). Sensitivity for detecting methylated alleles in a background of unmethylated alleles was determined by mixing DNA isolated from the CpGenome Universal methylated control with DNA isolated from the CpGenome Universal unmethylated control, to achieve 


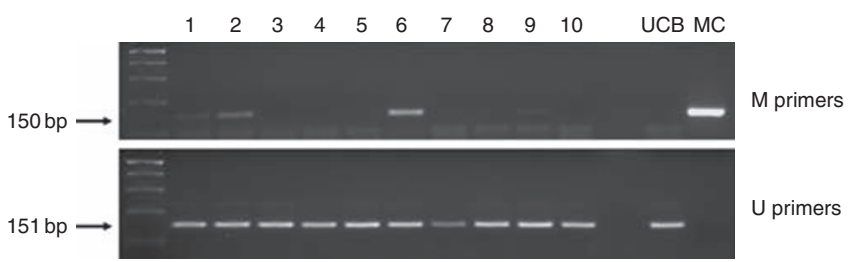

$\begin{array}{llllllllllll}11 & 12 & 13 & 14 & 15 & 16 & 17 & 18 & 19 & 20 & \mathrm{H}_{2} \mathrm{Oa} \mathrm{H} & \mathrm{H}\end{array}$

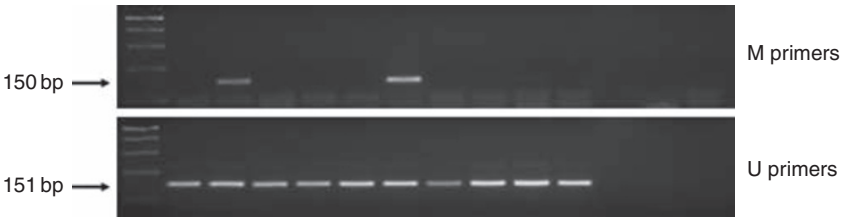

Figure 2 Representative results of the stage 2 PCR using methylated $(M)$ and unmethylated $(U)$ primers for the CDKN2A gene. Lanes I-20, cervical cytological samples taken from 20 women who were smokers. The presence of a $150 \mathrm{bp}$ product using the methylated primers indicates that the cytological sample was positive for CDKN2A methylation (samples I, 2, 6, 9, I2, and 16). CpGenome Universal Unmethylated DNA (vial B) (UCB) was used as a positive control for unmethylated DNA. CpGenome Universal Methylated DNA (MC) was used as a positive control for methylated DNA. $\mathrm{H}_{2} \mathrm{Oa}$, water from both stages of the nested methylationspecific PCR. $\mathrm{H}_{2} \mathrm{O}$, water from the stage $2 \mathrm{PCR}$ only.

dilutions of up to $1: 100000$. The mixed DNA samples were then subjected to bisulphite modification and subsequent analysis by nested methylation-specific PCR. The sensitivity of the nested methylation-specific PCR assay we used was $1: 1000$, similar to that reported elsewhere (Cirincione et al, 2006). To exclude false priming, that is, amplification of unmethylated alleles by the methylated primers, a subset of methylated products were analysed by direct sequencing: methylation of all $\mathrm{CpGs}$ within the CDKN2A primer sites was observed in every case. A sample was considered to be positive for $C D K N 2 A$ methylation when a methylated band was seen in both stage 2 PCR replicates using the methylated primers; negative for CDKN2A methylation when only an unmethylated band was detected; and non-evaluable when no band was seen using either the methylated or the unmethylated primers.

\section{Statistical analysis}

The matched analysis of the incidence of $C D K N 2 A$ methylation was undertaken using conditional logistic regression: confidence intervals for odds ratios were calculated using parameter estimates and their s.e.'s obtained from the model; statistical comparisons were made using the likelihood ratio test. All tests of statistical significance were conducted at the $5 \%$ two-sided significance level.

\section{RESULTS}

Of the 38 women who tested negative for CDKN2A methylation in the sample taken immediately before they began to smoke, eight tested positive for $C D K N 2 A$ methylation following smoking initiation; the median time to the first detection of CDKN2A methylation in those who acquired CDKN2A methylation was 266 days (inter-quartile range from 178 to 382 ). Each of the 38 women contributing to the incidence analysis was matched with two randomly selected never-smokers (controls) on length of follow-up (within 30 days); both groups were similar with respect to demographic and sexual behaviour characteristics (Table 1). For the eight women who first tested positive for methylated forms of CDKN2A after smoking initiation, the follow-up period was defined as the time interval between the date of the last
Table I Baseline characteristics of women in the matched cohort study

\begin{tabular}{lcc}
\hline Characteristic & $\begin{array}{c}\text { Incident smokers } \\
(\mathbf{n}=\mathbf{3 8})\end{array}$ & $\begin{array}{c}\text { Matched controls } \\
(\mathbf{n}=\mathbf{7 6})\end{array}$ \\
\hline Mean age (years) & 17.4 & 17.7 \\
No. of sexual partners (\%) & & \\
0 & $1(3)$ & $1(1)$ \\
1 & $20(53)$ & $56(74)$ \\
2 & $12(32)$ & $7(9)$ \\
3 & $5(13)$ & $9(12)$ \\
4 & $0(0)$ & $0(0)$ \\
5 & $0(0)$ & $1(1)$ \\
$>6$ & $0(0)$ & $2(3)$ \\
Mean no. of sexual partners & 1.9 & 1.1 \\
& & \\
Age at first sexual intercourse (years) $(\%)$ & $0(0)$ & $1(1)$ \\
$<13$ & $4(11)$ & $3(4)$ \\
14 & $5(13)$ & $8(11)$ \\
15 & $12(32)$ & $31(41)$ \\
16 & $10(26)$ & $19(25)$ \\
17 & $7(18)$ & $9(12)$ \\
18 & $0(0)$ & $4(5)$ \\
19 & $0(0)$ & $1(1)$ \\
Not applicable & 16.3 & 16.5 \\
Mean age at first sexual & & $2(2-2)$ \\
intercourse (years) & $2.5(2-6)$ & \\
Mean number of samples tested & & \\
(range) & & \\
\hline
\end{tabular}

unmethylated sample taken before smoking initiation and the date of the first sample to test positive for methylated forms of CDKN2A during that smoking episode, that is, while the woman continued to smoke. For the remaining 30 women who did not test positive for methylated forms of CDKN2A after they started to smoke, the follow-up period was defined as the time interval between the date of the last unmethylated sample taken before smoking initiation and the date of the last sample taken during that smoking episode. The first and last matched samples from each control were tested for the presence of methylated forms of $C D K N 2 A$. Three controls were excluded from subsequent analyses because of the presence of methylated forms of CDKN2A in the first of their two samples $(n=2)$ or because one of the two samples was not evaluable $(n=1)$. Of the remaining 73 controls who tested negative for methylated forms of CDKN2A in their first sample, five tested positive for these forms in their second sample. Compared with never-smokers, women who first started to smoke during follow-up had an increased risk of the acquisition of methylated forms of $C D K N 2 A$ (odds ratio $=3.67 ; 95 \%$ confidence interval $1.09-12.33 ; \chi^{2}=4.42 ; 1$ degree of freedom; $P=0.04$ ); controlling for number of sexual partners had no effect.

\section{DISCUSSION}

Using the cervix uteri as a model, we have shown that smoking increases the risk of acquiring methylated forms of CDKN $2 \mathrm{~A}$, a TSG, the epigenetic inactivation of which is strongly associated with the pathogenesis of neoplasia at many sites (Herman et al, 1995; Merlo et al, 1995). Our longitudinal study design and our unique study population (young women who had recently embarked on sexual activity and who tested negative for HPV DNA of any type and were cytologically free of disease) allowed us to reveal, for the first time, the relationship between an incident exposure (smoking initiation) and the subsequent appearance of an epigenetic change (methylation of CDKN2A). Such opportunities for demonstrating temporality in vivo come along rarely. The number of women in our original cohort was substantial, but 
inevitably this was attenuated when analyses were restricted to women who tested negative for HPV DNA of any type and were cytologically free of disease. Nevertheless by recruiting a cohort of women who first began to smoke during follow-up, we were able to show that this epigenetic change appeared soon after smoking initiation. So soon after smoking initiation, in fact, that had our analysis been restricted to women who were prevalent smokers at baseline, we might have failed to detect such an association in a longitudinal analysis in which observations were made at intervals of approximately 6 months.

Our findings are consistent with those of a cross-sectional study reporting a nonsignificant two-fold excess of methylated forms of $C D K N 2 A$ in normal cervical smears taken from smokers, compared with those taken from non-smokers; the higher prevalence of methylated forms of CDKN2A observed in our study may be because we used nested methylation-specific PCR, a more sensitive assay (Palmisano et al, 2000; Lea et al, 2004). Compared with never-smokers, current smokers who are cancer-free, but not necessarily disease-free, are also reported to have a higher prevalence of methylated forms of the TSGs fragile histidine triad (FHIT) and O-6-methylguanine-DNA methyltransferase (MGMT) in bronchial lavages and plasma, respectively (Kim et al, 2004; Belinsky et al, 2005).

In vitro studies in both untransformed and transformed cell lines show that short-term exposure to nicotine, or to cigarette smoke extract, is followed by changes in the expression of the DNA methyltransferases DNMT1, DNMT3A, and DNMT3B. These transcriptional changes have in turn been linked to the hypermethylation of FHIT, and to the demethylation of the oncogene synuclein-gamma (SNCG) (Soma et al, 2006; Liu et al, 2007).
In murine models of cigarette smoke-induced lung cancer, hypermethylation of the TSGs, death-associated protein kinase 1 $(D A P K 1)$ and the retinoic acid receptor beta $(R A R B)$, is seen at the earliest histological stage of adenocarcinoma development (Pulling et al, 2004; Vuillemenot et al, 2004).

Even allowing for possible inaccuracy in self-reporting, smoking behaviour is unlikely to account for all cases of CDKN2A methylation occurring in this cohort. In women who never smoked, epigenetic changes may be explained by other, as yet undefined, risk factors. For example, levels of airborne benzene have been associated with the methylation of p15 (CDKN1B) in healthy individuals (Bollati et al, 2007; Baccarelli et al, 2009).

Meta-analyses suggest that smoking cessation interventions have little effect on the behaviour of adolescents and young adults (Grimshaw and Stanton, 2006; Myung et al, 2009). Adolescent smokers largely discount distant health risks and consider people their own age invulnerable to the adverse effects of smoking (Balch, 1998; McVea et al, 2009). It has been argued that new information on the more immediate health effects of smoking is needed to challenge these disengagement beliefs (Kleinjan et al, 2009). This study provides such information.

\section{ACKNOWLEDGEMENTS}

We thank Stephanie Maloney for technical advice, Kaisheng Wen for technical support, and the women who took part in this study. This work was supported by Cancer Research UK (Grant no. C19200/A6072).

\section{REFERENCES}

Appleby P, Beral V, Berrington de González A, Colin D, Franceschi S, Goodill A, Green J, Peto J, Plummer M, Sweetland S, International Collaboration of Epidemiological Studies of Cervical Cancer (2006) Carcinoma of the cervix and tobacco smoking: collaborative reanalysis of individual data on 13541 women with carcinoma of the cervix and 23017 women without carcinoma of the cervix from 23 epidemiological studies. Int J Cancer 118: 1481 - 1495

Baccarelli A, Wright RO, Bollati V, Tarantini L, Litonjua AA, Suh HH, Zanobetti A, Sparrow D, Vokonas PS, Schwartz J (2009) Rapid DNA methylation changes after exposure to traffic particles. Am J Respir Crit Care Med 179: $572-578$

Balch GI (1998) Exploring perceptions of smoking cessation among high school smokers: input and feedback from focus groups. Prev Med 27: A55-A63

Belinsky SA, Klinge DM, Dekker JD, Smith MW, Bocklage TJ, Gilliland FD, Crowell RE, Karp DD, Stidley CA, Picchi MA (2005) Gene promoter methylation in plasma and sputum increases with lung cancer risk. Clin Cancer Res 11: 6505-6511

Bollati V, Baccarelli A, Hou L, Bonzini M, Fustinoni S, Cavallo D, Byun HM, Jiang J, Marinelli B, Pesatori AC, Bertazzi PA, Yang AS (2007) Changes in DNA methylation patterns in subjects exposed to low-dose benzene. Cancer Res 67: 876-880

Cirincione R, Lintas C, Conte D, Mariani L, Roz L, Vignola AM, Pastorino U, Sozzi G (2006) Methylation profile in tumor and sputum samples of lung cancer patients detected by spiral computed tomography: a nested case-control study. Int J Cancer 118: 1248-1253

Grimshaw GM, Stanton A (2006) Tobacco cessation interventions for young people. Cochrane Database Syst Rev 4: CD003289

Heijmans BT, Tobi EW, Stein AD, Putter H, Blauw GJ, Susser ES, Slagboom PE, Lumey LH (2008) Persistent epigenetic differences associated with prenatal exposure to famine in humans. Proc Natl Acad Sci USA 105: $17046-17049$

Herman JG, Merlo A, Mao L, Lapidus RG, Issa JP, Davidson NE, Sidransky D, Baylin SB (1995) Inactivation of the CDKN2/CDKN2A/MTS1 gene is frequently associated with aberrant DNA methylation in all common human cancers. Cancer Res 55: 4525-4530
Hwang LY, Ma Y, Benningfield SM, Clayton L, Hanson EN, Jay J, Jonte J, Godwin de Medina C, Moscicki AB (2009) Factors that influence the rate of epithelial maturation in the cervix in healthy young women. $J$ Adolesc Health 44: $103-110$

Kim DH, Kim JS, Ji YI, Shim YM, Kim H, Han J, Park J (2003) Hypermethylation of RASSF1A promoter is associated with the age at starting smoking and a poor prognosis in primary non-small cell lung cancer. Cancer Res 63: $3743-3746$

Kim H, Kwon YM, Kim JS, Lee H, Park JH, Shim YM, Han J, Park J, Kim DH (2004) Tumor-specific methylation in bronchial lavage for the early detection of non-small-cell lung cancer. J Clin Oncol 22: 2363-2370

Kleinjan M, van den Eijnden RJ, Engels RC (2009) Adolescents' rationalizations to continue smoking: the role of disengagement beliefs and nicotine dependence in smoking cessation. Addict Behav 34: 440-445

Lea JS, Coleman R, Kurien A, Schorge JO, Miller DS, Minna JD, Muller CY (2004) Aberrant CDKN2A methylation is a biomarker for tobacco exposure in cervical squamous cell carcinogenesis. Am J Obstet Gynecol 190: $674-679$

Liu H, Zhou Y, Boggs SE, Belinsky SA, Liu J (2007) Cigarette smoke induces demethylation of prometastatic oncogene synuclein-gamma in lung cancer cells by downregulation of DNMT3B. Oncogene 26: 5900-5910

Marsit CJ, Kim DH, Liu M, Hinds PW, Wiencke JK, Nelson HH, Kelsey KT (2005) Hypermethylation of RASSF1A and BLU tumor suppressor genes in non-small cell lung cancer: implications for tobacco smoking during adolescence. Int J Cancer 114: 219-223

McGowan PO, Sasaki A, D'Alessio AC, Dymov S, Labonté B, Szyf M, Turecki G, Meaney MJ (2009) Epigenetic regulation of the glucocorticoid receptor in human brain associates with childhood abuse. Nat Neurosci 12: $342-348$

McVea KL, Miller DL, Creswell JW, McEntarrfer R, Coleman MJ (2009) How adolescents experience smoking cessation. Qual Health Res 19: $580-592$

Merlo A, Herman JG, Mao L, Lee DJ, Gabrielson E, Burger PC, Baylin SB, Sidransky D (1995) $5^{\prime}$ CpG island methylation is associated with transcriptional silencing of the tumour suppressor CDKN2A/CDKN2/ MTS1 in human cancers. Nat Med 1: 686-692 
Myung SK, McDonnell DD, Kazinets G, Seo HG, Moskowitz JM (2009) Effects of Web- and computer-based smoking cessation programs: meta-analysis of randomized controlled trials. Arch Intern Med 169: $929-937$

Palmisano WA, Divine KK, Saccomanno G, Gilliland FD, Baylin SB, Herman JG, Belinsky SA (2000) Predicting lung cancer by detecting aberrant promoter methylation in sputum. Cancer Res 60: $5954-5958$

Perera F, Tang WY, Herbstman J, Tang D, Levin L, Miller R, Ho SM (2009) Relation of DNA methylation of $5^{\prime}-\mathrm{CpG}$ island of ACSL3 to transplacental exposure to airborne polycyclic aromatic hydrocarbons and childhood asthma. PLoS One 4: e4488

Pulling LC, Vuillemenot BR, Hutt JA, Devereux TR, Belinsky SA (2004) Aberrant promoter hypermethylation of the death-associated protein kinase gene is early and frequent in murine lung tumors induced by cigarette smoke and tobacco carcinogens. Cancer Res 64: $3844-3848$
Soma T, Kaganoi J, Kawabe A, Kondo K, Imamura M, Shimada Y (2006) Nicotine induces the fragile histidine triad methylation in human esophageal squamous epithelial cells. Int J Cancer 119: 1023-1027

Vuillemenot BR, Pulling LC, Palmisano WA, Hutt JA, Belinsky SA (2004) Carcinogen exposure differentially modulates RAR-beta promoter hypermethylation, an early and frequent event in mouse lung carcinogenesis. Carcinogenesis 25: 623-629

Wiencke JK, Kelsey KT (2002) Teen smoking, field cancerization, and a 'critical period' hypothesis for lung cancer susceptibility. Environ Health Perspect 110: 555-558

Wiencke JK, Thurston W, Kelsey KT, Varkonyi A, Wain JC, Mark EJ, Christiani DC (1990) Early age at smoking initiation and tobacco carcinogen DNA damage in the lung. J Natl Cancer Inst 91: 614-619

Woodman CB, Collins S, Winter H, Bailey A, Ellis J, Prior P, Yates M, Rollason TP, Young LS (2001) Natural history of cervical human papillomavirus infection in young women: a longitudinal cohort study. Lancet 357: $1831-1836$ 